\title{
A Case Base View of Heart Failure Predisposition Risk
}

\author{
Henrique Vicente ${ }^{1,2}$, M. Rosário Martins ${ }^{1,3}$, Margarida Duarte ${ }^{1}$, \\ Patrícia Miguel $^{1}$, José M. Grañeda ${ }^{4}$, Filomena Caldeira ${ }^{4}$, João Vilhena ${ }^{1}$, \\ João Neves ${ }^{5}$, and José Neves ${ }^{2(\bullet)}$ \\ 1 Departamento de Química, Escola de Ciências e Tecnologia, \\ Universidade de Évora, Évora, Portugal \\ \{hvicente,mrm\}@uevora.pt, margaridacorreiaduarte@hotmail.com, \\ patricia-alexandraa@hotmail.com, jmvilhena@gmail.com \\ 2 Centro Algoritmi, Universidade do Minho, Braga, Portugal \\ jneves@di.uminho.pt \\ ${ }^{3}$ Laboratório HERCULES, Universidade de Évora, Évora, Portugal \\ 4 Serviço de Patologia Clínica do Hospital do Espírito Santo de Évora EPE, Évora, Portugal \\ graneda1@sapo.pt, filomenacaldeiral@gmail.com \\ ${ }^{5}$ Mediclinic Arabian Ranches, 282602 Dubai, United Arab Emirates \\ joaocpneves@gmail.com
}

\begin{abstract}
Heart failure stands for an abnormality in cardiac structure or function which results in the incapability of the heart to deliver oxygen at an ideal rate. This is a worldwide problem of public health, characterized by high mortality, frequent hospitalization and reduced quality of life. Thus, this work will focus on the development of a decision support system to assess heart failure predisposing risk. The framework is built on top of a Logic Programming approach to Knowledge Representation and Reasoning, complemented with a Case Based approach to computing. The proposed solution is unique in itself, once it caters for the explicit treatment of incomplete, unknown, or even self-contradictory information, either in terms of a qualitative or quantitative setting. Furthermore, clustering methods based on similarity analysis among cases were used to distinguish and aggregate collections of historical data or knowledge in order to reduce the search space, therefore enhancing the cases retrieval and the overall computational process. The proposed model classifies properly the patients exhibiting accuracy and sensitivity higher than $90 \%$.
\end{abstract}

Keywords: Heart failure - Logic programming - Case-Based reasoning · Knowledge representation and reasoning - Decision support systems 